\title{
Changes in Body Position during a 2-Minute Push-Up Test
}

\author{
Jennifer K Hewit*, Daniel A Jaffe and Alex J Bedard \\ Department of Physical Education, United States Military Academy at West Point, USA
}

*Corresponding author: Jennifer K. Hewit, Ph.D, Assistant Professor, Department of Physical Education Director of the Human Performance Lab, United States Military Academy at West Point, USA

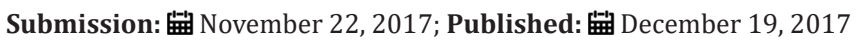

\begin{abstract}
Push-ups are a common exercise for individuals of all ages and abilities. Ensuring that the body maintains optimal positioning is crucial throughout any activity. This brief study investigates the changes in hand height and torso angle throughout a 2-minute push-up test. A total of 26 males (23.3 \pm 6.9 years old) participated in this study. Video was collected of the entire 2-minute push-up bout. Of interest to the researchers was the distance the hand was in relation to the shoulder and the angle of the torso to the horizontal (both measure from participants' sagittal view). Three consecutive repetitions at the start and end of the bout were used for comparative analysis. Both hand placement in relation to the shoulder and torso angle decreased significantly $(\mathrm{p}=0.00)$ from the start of the bout to the end. These results indicate that as participants became tired, they assumed a body position that likely allowed for a greater portion of their body weight to be supported by their lower body. While this adjustment allowed them to continue the exercise, compensational patterns like this should be identified and addressed in training in order to strengthen the primary muscles targeted by the exercise.
\end{abstract}

Keywords: Hand height; Torso angle; Form; Technique; Assessment; Muscular endurance; Body angles; Hand position

Abbreviations: Hand Ht: Hand Height in relation to the shoulder; Torso: Torso angle to the horizontal

\section{Introduction}

The push-up exercise is a common fundamental exercise used to train and assess the muscular endurance of the entire body [1-4]. Due to the emphasis on body control and ease of administration, this exercise has been performed regularly for decades by a wide variety of athletes, military personnel, and recreational fitness enthusiasts alike. The standardized 2-minute push-up test has been performed by all active duty U.S. Army Soldiers and reservists as part of the Army Physical Fitness Test (APFT) every 6 months for almost 40 consecutive years [5], with the total number of repetitions completed to standard recorded for each participant. While technique is anticipated to deteriorate over the course of the bout, being able to maintain proper body positioning for as long as possible is desirable as it will likely increase the number of repetitions recorded.

While extensive research has investigated differences in initial hand placement, joint stresses and optimizing training effectiveness [6-18], little attention has been given to the changes in body position over the course of an extended push-up bout when compensational movement patterns are likely to be adopted. Therefore, the purpose of this article was to compare the natural push-up body positioning from the beginning to the end of a continuous 2-minute standardized push-up assessment. To the knowledge of the authors of this study, there is currently no research published that investigates body positioning changes adopted throughout the course of a push-up test. As technical standards for push-ups vary considerably among researchers and sports professionals, the APFT push-up guidelines were used as the standardized push-up protocol for this movement analysis [19].

\section{Materials and Methods}

\section{Subjects}

A total of 26 males (height: $1.76 \pm 8.6 \mathrm{~m}$, weight: $84.2 \pm 11.3 \mathrm{~kg}$; age: $23.3 \pm 6.9$ years) from the United States Military volunteered to participate in this study. All participants were free of injury at the time of testing. Prior to participation, informed written consent was obtained from each participant. All procedures were approved by the Human Research Protection Program before commencing the study.

\section{Testing protocol}

Following a self-selected warm-up, each participant assumed the front leaning rest position (i.e. plank position) when ready. On the researcher's command, participants performed as many pushups as they were able to within the allotted 2-minute time period. At no time were participants allowed to drop their knees to the ground. However, resting in pike position (i.e. downward dog) or 
the front leaning rest position was allowed as needed. The hands were allowed to be repositioned as needed by sliding them across the testing surface. Additionally, push-ups were only counted if

1) The upper arm reached parallel (or lower) to the ground during the downward phase of the movement,

2) The elbow reached full extension in the front leaning rest position after each repetition, and

3) The body moved as one unit, forming a straight line from head to ankles throughout the movement.

Upon completion of the 2-minute exercise bout, participants were asked to perform a self-selected cool-down on their own before leaving the lab.

One camera recorded the entire 2-minute bout for each participant. The camera was placed on the right side of the body, in line with the participants' shoulder. Two measurements from this camera were of interest to the researchers for this analysis:

1) The distance from the heel of the hand to the shoulder (Hand $\mathrm{Ht}$ ), and

2) The torso angle to the horizontal at the start of each repetition (Torso) (Figure 1).

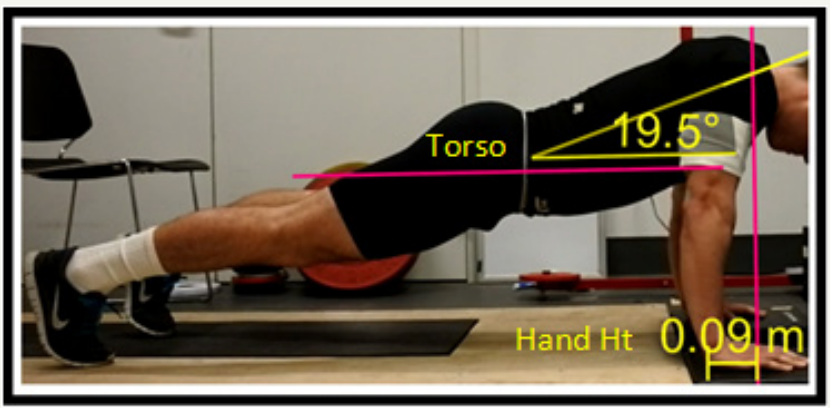

Figure 1: Measurements of interest: hand height in relation to the shoulder (Hand ht) and Torso angle to the horizontal (Torso).

Reflective markers were placed at the acromion process and iliac crest for measurement purposes.

\section{Statistical analyses}

Measurements (Torso and Hand Height) were recorded and averaged over the $2^{\text {nd }}, 3^{\text {rd }}$ and $4^{\text {th }}$ repetition and the $4^{\text {th }}, 3^{\text {rd }}$ and $2^{\text {nd }}$ to last repetition. Paired t-tests were used to determine if there was significant difference in these measures from the beginning to the end of the bout. Statistical significance was set at $p \leq 0.05$.

\section{Results and Discussion}

At the beginning of the assessment, participants began with their hands (Hand $\mathrm{Ht}$ ) positioned significantly lower (66\%) in relation to the shoulder than at the end of the bout $(\mathrm{t}(25)=3.0, \mathrm{p}$ $=0.00, d=0.73$ ), (Table 1). This initially indicated that the hands were repositioned to a higher placement during the exercise, likely in an attempt to lessen the strain and fatigue being experienced by the muscles (e.g. pectorals and triceps) $[4,20]$. However, when viewing the video footage participants' hands were not actually repositioned at all throughout the bout, indicating that some other adjustment must have been made during the course of the exercise.

Table 1: Hand height (Hand $\mathrm{Ht}$ ) and torso angle to the horizontal (Torso) at the start and end of a 2-minute continuous push-up bout.

\begin{tabular}{|c|c|c|c|}
\hline Measurement & Start Mean \pm SD & End Mean \pm SD & p-value \\
\hline Hand Ht $(\mathrm{cm})$ & $10.8 \pm 5.4$ & $6.8 \pm 5.6$ & $0.00^{*}$ \\
\hline Torso (degrees) & $24.7 \pm 6.5$ & $17.8 \pm 8.8$ & $0.00^{*}$ \\
\hline
\end{tabular}

*Indicates significance at the $\mathrm{p} \leq 0.05$ level

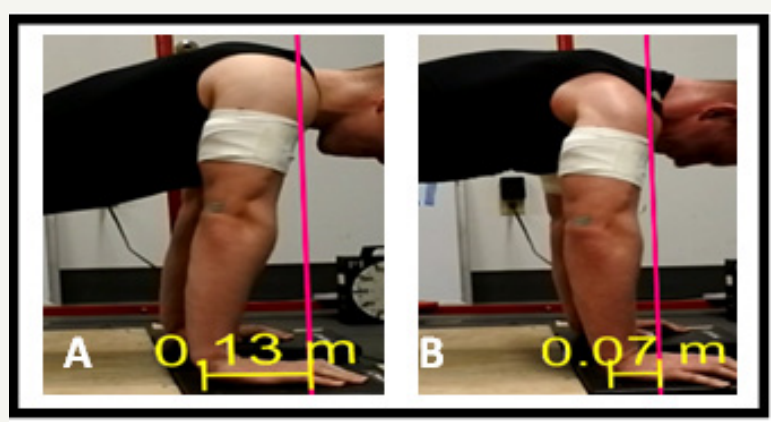

Figure 2: Representative subject's hand height in relation to the shoulder at the start (A) and end (B) of the bout.

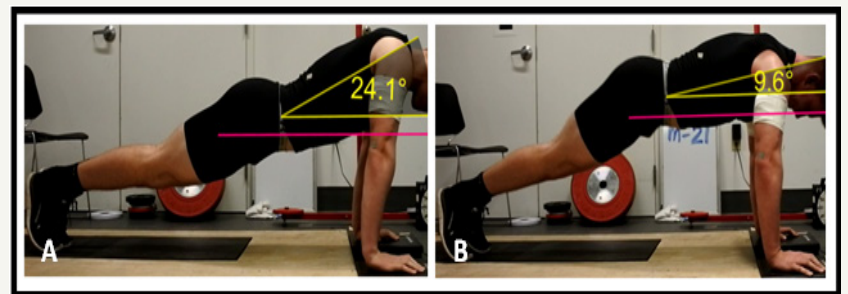

Figure 3: Representative subject's torso angle in relation to the horizontal at the start (A) and end (B) of the bout.

Similarly, the angle of the torso (Torso) to the horizontal was also found to decrease significantly (72\%) throughout the bout $(\mathrm{t}(25)=5.1, \mathrm{p}=0.00, \mathrm{~d}=0.89)$. As participants began to experience fatigue, they adopted a more horizontal torso position through increased hip flexion. This combined with the hands positioned closer to the shoulder at the end of the bout indicated that as participants began tire, they did not fully return to the front leaning rest position. At the beginning of the exercise, a greater percent of body weight is likely supported by the upper body as the hands were positioned more in line with the chest as opposed to the shoulders (Figure 2). The altered body position at the end of the bout (Figure 3) likely allowed for a greater percent of the body weight to be supported by the lower body (similar to the modified push-up position), thereby relieving some of the strain to the muscles of interest (i.e. pectorals and triceps) $[1,3,4]$.

\section{Conclusion}

Attention to technical characteristics of push-up performance is often focused on the optimal starting execution position (e.g. 
hand position, upper arm angle, etc.). However, over the course of an assessment that is meant to challenge the muscular endurance of an athlete, it is reasonable to assume that compensational movement patterns (e.g. piking at the hips, hand placement higher than shoulder height, etc.) will likely be adopted once the primary muscles (i.e. pectorals and triceps, and core musculature) begin to fatigue in order to continue the exercise. It is important to identify these compensational strategies so that training can target the areas of deficiency. If an athlete begins to display such assistive movement patterns, it is advised that the exercise be stopped and additional muscular endurance training be implemented. Athletes should be aware of their body positioning throughout any exercise. In addition to verbal feedback, coaching tools such as mirrors and video cameras (e.g. cell phones and tablets) are recommended as a means of immediate visual feedback during training sessions to promote proper body alignment and spatial awareness.

\section{References}

1. Mier C, Tal A, Capehart S, Garner H (2014) Differences between men and women in percentage of body weight supported during the push-up exercise. International Journal of Exercise Science 7(2): 161-168.

2. Topalidou A, Dafopoulou G, Klepkou E, Aggeligakis J, Bekris E, et al. (2012) Biomechanical evaluation of the push-up exercise of the upper extremities from various starting points. Journal of Physical Education and Sport 12(1): 71-80.

3. Ebben W, Wurm B, Vander Zanden TL, Spadavecchia ML, Durocher JJ, et al. (2011) Kinetic analysis of several variations of push-ups. J Strength Cond Res 25(10): 2891-2894.

4. Gouvali M, Boudolos K (2005) Dynamic and electro myographical analysis in variants of push-up exercise. Journal J Strength Cond Res 19(1): 146-151.

5. Knapik J, East W (2014) History of the United States Army physical fitness and physical readiness training. US Army Med Dep J, pp. 5-19.

6. Marshall, P, Murphy B (2006) Changes in muscle activity and perceived exertion during exercises performed on a swiss ball. Appl Physiol Nutr Metab 31(4): 376-383.

7. An K, Chao EY, Morrey BF, Donkers MJ (1992) Inter segmental elbow joint load during the push-up. Biomed Sci Instrum 28: 69-74.
8. San Juan J, Suprak DN, Roach SM, Lyda M (2015) The effects of exercise type and elbow angle on vertical ground reaction force and muscle activity during a push-up plus exercise. BMC Musculoskeletal Disord 16(23): 1-9.

9. Mok K, Anna C, Yung P, Chan KM (2017) Are the muscle activations different in various types of push-up exercise? British Journal of Sports Medicine 51(4): 363-364.

10. Lehman G, MacMillan B, MacIntyre I, Chivers M, Fluter M (2006) Shoulder muscle EMG activity during push-up variations on and off a swiss ball. Dyn Med 5(7): 1-7.

11. Anderson, G., Geatez M, Holzmann M, Twist P (2013) Comparison of EMG activity during stable and unstable push-up protocols. European Journal of Sport Science 13(1): 42-48.

12. Sandhu J, Mahajan S, Shenoy S (2008) An electromyographic analysis of shoulder muscle activation during push-up variations on stable and labile surfaces. Int J Shoulder Surg 2(2): 30-35.

13. Marcolin G, Petrone N, Moro T, Battaglia G, Bianco A, et al. (2015) Selective activation of shoulder, trunk, and arm muscles: A comparative analysis of different push-up variants. J Athl Train 50(11): 1126-1132.

14. Donkers M, Chao E, Morrey B (1993) Hand position affects elbow joint load during push-up exercises. J Biomech 26(6): 625-632.

15. Chou P, Hsu H, Chen S, Yang S, Kuo C, et al. (2011) Effect of push-up speed on elbow joint loading. Journal of Medical and Biological Engineering 31(3): 161-168.

16. Kim Y, Kim D, Ha M (2016) Effect of the push-up exercise at different palmar width on muscle activities. J Phys Ther Sci 28(2): 446-449.

17. Calatayud J, Borreani S, Colado JC, Martín FF, Rogers ME, et al. (2014) Muscle activation during push-ups with different suspension training systems. J Sports Sci Med 13(3): 502-510.

18. Cogley R, Archambault TA, Fibeger JF, Koverman MM, Youdas JW, et al. (2005) Comparison of muscle activation using various hand positions during the push-up exercise. J Strength Cond Res 19(3): 628-633.

19. Army Physical Fitness Test (APFT) (2013) in Army Physical Readiness Training. U.S. Department of the Army: Washington, USA, pp. 341-347.

20. Borreani S, Calatayud J, Colado JC, Tella V, Moya-Nájera D, et al. (2015) Shoulder muscle activation during stable and suspended push-ups at different heights in healthy subjects. Phys Ther Sport 16(3): 248-254. 